\title{
The Beginning of Big Sciences in Physics: The Price to Pay
}

\author{
Joseph Kouneiher* and Cécile Barbachoux ${ }^{\dagger}$ \\ ARTEMIS, UMR 7250 (OCA, UCA, CNRS) \\ Université Côte d'Azur, France \\ *joseph.kouneiher@unice.fr \\ †cecile.barbachoux@unice.fr
}

Received 3 November 2016

Accepted 5 February 2017

Published 10 April 2017

As long as there is freedom of research, there is the responsibility that comes with it

\begin{abstract}
In this paper, we want to trace back the actual changes concerning the relations between physics in particular and sciences in general with socio-economical and technological evolution of the societies. Our main idea is that those changes started with the Atomic Bomb project and the beginning of big sciences mostly and in some degree it is a legacy of the implication of some scientific Laboratories in the World War I and II.
\end{abstract}

Keywords: Big sciences; sciences management; sciences governance; scientize politics; politicized sciences; freedom and responsibility; planned obsolescence and progress; Manhattan Project; value in sciences; knowledge-based economy.

\section{Introduction}

After the World War II, the world witnessed increasing amounts of knowledge and the establishment of new scientific disciplines, abilities and applications which have changed modern research landscape. Thereby, the increasing public interest in and scrutiny of scientific research is the direct result of an exponential growth in the knowledge of Nature, mankind, society and history that science has produced since the 19th century. ${ }^{1}$ This huge amount of knowledge has profoundly changed our natural and social environment through its manifold technological, medical and other applications. The basis for all these technologies is knowledge, which comes from research through observation, experimentation, computer simulations and other methodologies. However, the process of knowledge creation, which encodes a

This is an Open Access article published by World Scientific Publishing Company. It is distributed under the terms of the Creative Commons Attribution 4.0 (CC-BY) License. Further distribution of this work is permitted, provided the original work is properly cited. 
profound meaning for the relationship between science and society, based on debate and discourse, not only results in credibility, quality and public acceptance of science, but also in irritation and misuse and even abuse by politics, which arise particularly in the context of expert knowledge.

It is a common knowledge that the scientific community has its own internal power structures, its elites, its hierarchies, its ideologies, its sanctioned norms of social behavior, and its dissenting groups. With the new politics of science, the more that science, as a social practice, forms an integral part of the economic structures of the society in which it is imbedded, the more the boundaries and differences between the two dissolve. Groups inside the scientific community, for example, will use groups outside the community — and vice versa - to achieve their own political ends. Think about the continuing and increasing influence of industrial and defense interests on the scientific research of each country since 1980s.

By building the nuclear bomb, physicists brought scientific discovery into contact with technological invention and thereby transgressed the boundaries of scientific purity. Attempting to shape the postwar implications of their invention, the physicists themselves entered the political realm to advocate the need for international unification, atomic control, and a ban on war.

The physicists acknowledged that science would play a more central role in the structure of society, and many decided that the culture of science had to make accommodating changes by taking responsibility for the practical results of laboratory exploration. The physicists' political arguments, however, were rooted in the ethos of science and therefore inapplicable to national governance and international diplomacy. Furthermore, the physicists' attempt to "scientize" politics invited the reciprocal action wherein science was "politicized": military-political administrators regimented, funded, and directed "free" scientific exploration. Manhattan Project physicists were made suspects of indiscretion because the scientific tenets of internationalism and free exchange of information seemed disloyal in the 1940s.

The unprecedented case of the Manhattan Project physicists' political activity before Hiroshima highlights both the capacity of scientists to assume social responsibility for science and the limitations of their profession in the political realm. In doing so, it explains how the notion of scientific purity was transformed, how the practice of physicists has changed over time, and where these two elements may go in the future.

Indeed, many experiences have demonstrated how important it is to build a lively relationship between science and the media. Such initiatives to close the gap between science and the public will become even more important because scientific research is undergoing a transition. In a traditional sense, the credibility of science seems to be linked to its task and its commitment to seek the truth.

The basic principle of [science] is that the pursuit of knowledge is the most worthy of all human activities. Simply to acquire knowledge is an end in itself. 
This doctrine is usually expressed in the form: research should be undertaken for its own sake. That is to say, science is disconnected from all other human activities or concerns and has significance only in and for itself. ${ }^{2}$

But this relationship between science and truth, a heritage from the European history of science, is put into different perspectives by science itself. ${ }^{2}$ Even the best experimental data can be very short-lived, and researchers have learned to regard this data as true only until new data become available. Now, in many domains of sciences, research scientists are used to working with parallel realities as a result of complex, self-organizing systems that can be described on different levels, such as molecular and cellular systems or behavior. In this way, the quest for absolute truth is increasingly replaced by establishing robust or reliable knowledge.

It is too early to say if this means a paradigm shift in scientific research. It is a fact that the process of knowledge production is changing. Research is conducted more and more under the influence of non-scientific organizations and industry, which is not necessarily a bad development as it allows science to increase its efficiency with limited funds. However, it is not correct to assume that scientists live a blessed life in an ivory tower, in which they have all necessary resources to hand. An active researcher is an entrepreneur who has to manage production, research, personnel, finances, marketing and the sale of his or her product in an international and highly competitive market.

Our aim in this paper is to show how the massive involvement of the physical communities in the Bomb Atomic project and the changes in the mentality of this communities opened the doors widely towards the idea of "Big Projects and Big sciences in the Cities". ${ }^{26,29}$ The results will be manifold and the calling for a management politics of the governance of the universities today is only a residual effect of the ongoing evolution of this changed mentality inside sciences. ${ }^{25}$

\section{Sciences and Politics Power Between Conflict and Allies}

At its heart, politics is about getting a group of people to agree (or at least acquiesce) in a common course of action. This generally requires some prior consensus about the source of legitimacy in decision-making.

The word politics comes from the Greek word "polis", meaning the state or community as a whole. The concept of the "polis" came from the writings of great political thinkers such as Plato and Aristotle. In his novel "The Republic", Plato describes the ideal state and the means to achieve it. Hence, the word politics originally has connotations in the ways to create the ideal society. An ideal society is in practice a rather difficult aim and even an impossible aim to achieve. So we can consider that the imperfections in the societies, in which Plato and Aristotle lived, prompted them to write their political philosophies. These philosophies provided the first written recognition of politics. 
There is, we guess, no wholly rational and evidence-based source of legitimacy in any political system. All, to a greater degree or lesser, resort to dogma in some form. Dogma is defined as a belief that is beyond question. Religions are dogmatic by nature and thus are frequently co-opted as a source of political legitimacy, but ideologies sometimes approach religious levels of dogmatic content and can also be used to legitimate authority.

Now, an essence of science, like the discipline of philosophy from which it grew, is to ask questions. Science builds on philosophy by privileging observation, particularly experimental observation, as the preferred form of answering questions. But science still starts with questions.

Naturally enough, politics, which requires dogma, and science, which requires questions, are bound to come in conflict. We all know how Socrates was forced to take poison for disrupting public order with his questions; how Galileo was forced to recant the heliocentric theory of planetary movement; how Mendelian genetics were suppressed under Stalin as contravening Marxist dogma.

The practice of suppressing science exists also in the liberal democracies, most notably the most religious one: the USA. ${ }^{8}$ The administration of George W. Bush made this practice an integral component of their governing strategy, especially in the following areas:

- Global warming, where reports by the Environmental Protection Agency on the risks of climate change were suppressed;

- Missile defense, where Defense Department officials presented misleading information on whether a functional system could be quickly deployed; and

- Wetlands policy, where comments from scientists at the Fish and Wildlife Service on the destructive impacts of proposed regulatory changes were withheld.

It is fair enough to say that science is strong only when dogma is weak. To the extent that political systems rely on dogma as a source of legitimacy, they will inevitably conflict with science and scientists, and act to suppress them.

In many countries, people depend upon federal or public agencies to promote scientific research and to develop science-based policies that protect the nations health and welfare. Historically, these agencies have had global reputations for scientific excellence. However, leading scientific and journals start asking (ad even before) the question whether scientific integrity at federal agencies has been sacrificed to further a political and ideological agenda. Indeed, we find today a growing evidence that the Administrations "invades areas once immune to this kind of manipulation." For instance, the cases of Scientific advisory committees which assure that the government hears from the nations top experts in a particular field before creating policy in that area. Ideally, committees must be "fairly balanced in terms of the points of view represented" and requires that advice and recommendations "not be inappropriately influenced by the appointing authority or by any special interest." However, we saw in many countries some Administrations has 
repeatedly manipulated the advisory committee process to advance its political and ideological agenda. Examples include, Appointing (Un)qualified Persons with Industry Ties, Appointing (Un)qualified Persons with Ideological Agendas, Stacking Advisory Committees, Opposing Qualified Experts, Distorting and Suppressing Scientific Information. Promote projects carried out by persons or scientists close to political power. For more about recruit sciences in different domains of financial sector: banks, stock markets and economy, drug industry, etc. see please. ${ }^{\text {a } 5}$

\subsection{The Galileo affair}

Europe of the 16th and 17th centuries was witness of what we recognized later as the Scientific Revolution. A period where people witnessed an explosion of discoveries about the natural world, therefore modern science was born. During this period, men such as Copernicus, Galileo, Vesalius, Harvey, Newton and countless others made discoveries in fields such as astronomy, anatomy, kinematics, dynamics and physiology. New instruments were invented and perfected to achieve new and better observations; these included the telescope, microscope, thermometer, barometer, precision clock and air-pump. A new type of social organization was created, the scientific society.

To understand the real impact of Copernicus breakthrough let us consider the prevailing attitude toward science when Galileo began his work. Since the time of the Greeks, the purpose of astronomy was to "save the appearances" c of celestial phenomena. So, the almost universal belief that the purpose of science was not to give a final account of reality, but merely to "save appearances," accounts for how lightly the Church hierarchy initially received Copernicus's theory. Astronomy and mathematics were regarded as the play things of virtuosi. They were accounted as having neither philosophical nor theological relevance. It was all one to them how the "appearances" were "saved." And, in fact, Copernicus, a good Catholic, published his book at the urging of two eminent prelates and dedicated it to Pope Paul III, who received it cordially.

But in reality Copernicus's book marked a sea change in human thought. Copernicus (probably — it cannot be regarded as certain) began to think, and

\footnotetext{
a We want to thank the referee for those excellent suggestions.

$\mathrm{b}$ The discoveries in astronomy and physics led to the grand Newtonian synthesis - a set of laws of motion which implied a reconceiving of the universe itself. The official Christian cosmology was shattered. Perhaps, most importantly, a new method of scientific discovery itself had been discovered - a method based on careful observation, experimentation, and mathematics - a method in which faith and obedience to religious authority played no role whatsoever.

c This famous phrase is usually taken to mean the resorting to desperate expedients to "save" or rescue the Ptolemaic system. But it meant no such thing. To the Greek and medieval mind, science was a kind of formalism, a means of coordinating data, which had no bearing on the ultimate reality of things. Different mathematical devices such as the Ptolemaic cycles could be advanced to predict the movements of the planets, and it was of no concern to the medieval astronomer whether such devices touched on the actual physical truth. The point was to give order to complicated data, and all that mattered was which hypothesis (a key word in the Galileo affair) was the simplest and most convenient.
} 
others, like Kepler and Galileo, began to affirm that the heliocentric hypothesis not only saved the appearances, but was physically true... It was not simply a new theory of the nature of celestial movements that was feared, but a new theory of the nature of theory; namely, that, if a hypothesis saves all the appearances, it is identical with truth.

In 1633, at the conclusion of one of history's most famous trials, the Roman Inquisition found Galileo guilty of "vehement suspicion of heresy"; this was a specific category of religious crime intermediate in seriousness between formal heresy and mild suspicion of heresy. He had committed this alleged crime in a book that defended Copernicus's hypothesis of the earth's motion and denied the scientific authority of Scripture ${ }^{\mathrm{d}}$; this work had been published the previous year, under the title Dialogue on the Two Chief World Systems, Ptolemaic and Copernican. This verdict was accompanied by several penalties: Galileo had to immediately recite an "abjuration" of his erroneous beliefs; the Dialogue was banned; he was condemned to house arrest to the end of his life; and he had to recite the seven penitential psalms once a week for three years. ${ }^{9}$

At this point, we must point out the attitude of some scientists and intellectuals close to the Roman power at the moment and who would try to take advantage of the situation. Indeed, this is the case of the meddlesome and ambitious Dominican priest, Thomas Caccini, who preached a fiery sermon in Florence denouncing Copernicanism and science in general as contrary to Christian faith. The attack was clearly aimed at Galileo. About a month later, another Domincan, Father Niccolo Lorini, read a copy of Galileo's Letter to Castelli and was disturbed to find that Galileo had taken it upon himself to interpret Scripture according to his private lights. He sent a copy to the Inquisition in Rome-one, but the Consultor of the Holy Office (or Inquisition) nevertheless found no serious objections to the letter and the case was dismissed.

A month later, Caccini appeared in Rome uninvited, begging the Holy Office to testify against Galileo. Arthur Koestler writes that "Caccini beautifully fits the satirist's image of an ignorant, officious, and intriguing monk of the Renaissance. Caccini's testimony were on the files of the Inquisition, and Rome was buzzing with rumors that the Church was going to condemn both Galileo and Copernicanism. Galileo's friends in the hierarchy, including Cardinal Barberini, the future

\footnotetext{
d In 1614, Galileo felt that he had to answer the objection that the new science contradicted certain passages of Scripture. There was, for example, Joshua's command that the sun stand still. Why would Joshua do that if, as Galileo asserted, the sun didn't move at all? Then there were Psalms 92 ("He has made the world firm, not to be moved.") and 103 ("You fixed the earth upon its foundation, not to be moved forever."), not to mention the famous verse in Ecclesiastes. These are not obscure passages, and their literal sense would obviously have to be abandoned if the Copernican system were true. Galileo accepted the inerrancy of Scripture; but he was also mindful of Cardinal Baronius's quip that the bible "is intended to teach us how to go to heaven, not how the heavens go." And he pointed out correctly that both St. Augustine and St. Thomas Aquinas taught that the sacred writers in no way meant to teach a system of astronomy.
} 
Urban VIII, warned him not to force the issue. But Galileo only intensified his campaign to get the Church to accept Copernicanism as an irrefutable truth".

Thus, one can see how the central power or the administration can manipulate using certain close scientists or people to question the truth.

To the popular mind, the Galileo affair is prima facie evidence that the free pursuit of truth became possible only after science "liberated" itself from the theological shackles of the Middle Ages. The case makes for such a neat morality play of enlightened science versus dogmatic obscurantism that historians are seldom tempted to correct the anti-Catholic "spin" that is usually put on it. Even many intelligent Catholics would prefer that the whole sorry affair be swept under a rug. This is not, however, the attitude of Pope John Paul II. In 1979, he expressed the wish that the Pontifical Academy of Sciences conduct an in-depth study of the celebrated case. What John Paul II wanted was a better understanding of the whole affair by both scientists and theologians. He pointed out that

"the Galileo case has been a sort of "myth," in which the image fabricated out of the events was quite far removed from the reality. In this perspective, the Galileo case was the symbol of the Church's supposed rejection of scientific progress."

Galileo's run-in with the Church, according to the Pope, involved a "tragic mutual incomprehension" in which both sides were at fault.

Albert Einstein supported the compatibility of some interpretations of religion with science. In "Science, Philosophy and Religion, A Symposium" published by the Conference on Science, Philosophy and Religion in Their Relation to the Democratic Way of Life, Inc., New York in 1941, Einstein stated:

Accordingly, a religious person is devout in the sense that he has no doubt of the significance and loftiness of those superpersonal objects and goals which neither require nor are capable of rational foundation. They exist with the same necessity and matter-of-factness as he himself. In this sense religion is the age-old endeavor of mankind to become clearly and completely conscious of these values and goals and constantly to strengthen and extend their effect. If one conceives of religion and science according to these definitions then a conflict between them appears impossible. For science can only ascertain what is, but not what should be, and outside of its domain value judgments of all kinds remain necessary. Religion, on the other hand, deals only with evaluations of human thought and action: it cannot justifiably speak of facts and relationships between facts. According to this interpretation the well-known conflicts between religion and science in the past must all be ascribed to a misapprehension of the situation which has been described [161].

Einstein, thus expresses views of ethical non-naturalism (contrasted to ethical naturalism). 


\subsection{Tesla Case!}

Tesla case is very distinguished case and exceptional because of Tesla personality high in color. Tesla, a Serbian by parentage, began working for the phone company in Budapest. In 1882, he headed for Paris, where he took a job with the Continental Edison Company. He was invited to work stateside after his supervisor wrote a recommendation praising the young man as a genius on par with Edison himself. While he hired Tesla, Edison thought the man's ideas were splendid but utterly impractical.

Tesla was interested more in broad concepts than practical inventions. He was obsessed with providing the world with omnipresent, always available and free energy. His work was essential for Radio (Marconi lost the patent battle), X-rays, remote control, neon lights and many more, but his legacy is power distribution system based on alternate current (AC). He won the "War of the Currents" against Edison and even today it is the most reliable, safest and most efficient way to distribute electricity to every house, building or factory. His most valued invention was electro-magnetic motor, the engine for big generators at Westinghouse's ${ }^{\mathrm{e}}$ power station at Niagara falls, the first in the world, sending light and power to Buffalo and the whole 20 th century. ${ }^{11}$

Tesla, was an emotionally driven dreamer with years of engineering training, which allowed him to work out theories before physically implementing them. Edison, in contrast relied heavily on tedious experimentation for most of his discoveries, a commitment which some historians attribute partially to his lack of formal education. Edison, without question, he wasn't the only person to invent the light bulb, or recorded sound, or moving pictures, but he's the one who turned them into whole industries. He also discovered the Edison Effect, which is the principle by which vacuum tubes work. Although he didn't understand its implications or market it, the discovery was the basis for amplifiers, which were hugely important in the development of electronic equipment.

Later in life, each man publicly criticized the others work. Tesla on Edison:

"If he had a needle to find in a haystack, he would not stop to reason where it was most likely to be, but would proceed at once, with the feverish diligence of a bee, to examine straw after straw until he found the object of his search. ... I was almost a sorry witness of such doings, knowing that a little theory and calculation would have saved him ninety per cent of his labor." New York Times, 19 October 1931 (the day after Edison died)

\footnotetext{
e Westinghouse was a systems thinker, he also had a knack for spotting good ideas and people and bringing them into his fold, and he knew AC power distribution was a good idea. In 1885, Westinghouse became interested in the inventions of European Inventors Gaulard and Gibbs and purchased the American rights to their patents for AC current transformers. George Westinghouse and Nikola Tesla had a mutual respect for each other, but eventually Tesla's inability to work as a member of a team strained their relationship, and Tesla moved on.
} 
Nevertheless, Edison and Tesla were alike in some equally irreconcilable ways. Both were egocentrics who abhorred egocentricity in others. And both men required little sleep, which would have made for many long, grumpy hours in the workshop. Note that Edison and George Westinghouse clearly possessed the one trait that Tesla did note - a mind for business. Edison, as Morgan, he had a privileged relations with the American administration and even a sensitive position in the marine. ${ }^{\mathrm{f}}$

Several times Tesla was able to have grants to accomplish some of his projects, for example, continued to work on his ideas for wireless transmissions tempting a dramatic attempt to change the future of communications and power transmission around the world. He managed to convince J. P. Morgan that he was on the verge of a breakthrough, and the financier gave Tesla more than 150,000 dollars to fund what would become a gigantic, futuristic and startling tower in the middle of Long Island, New York. In 1898, as Tesla's plans to create a worldwide wireless transmission system became known, Wardenclyffe Tower would be Tesla's last chance to claim the recognition and wealth that had always escaped him. But soon after construction began it became apparent that Tesla was going to run out of money before it was finished. An appeal to Morgan for more money proved fruitless. ${ }^{12}$ Unfortunately, when the objectives and the interest of the works of Tesla are removed from those of the mainstream and the administration Tesla lost any support or investment. In the meantime, investors were rushing to throw their money behind Marconi. In December 1901, Marconi successfully sent a signal from England to Newfoundland. Tesla grumbled that the Italian was using 17 of his patents, but litigation eventually favored Marconi and the commercial damage was done. (The US Supreme Court ultimately upheld Tesla's claims, clarifying Tesla's role in the invention of the radio but not until 1943, after he died.) Thus, the Italian inventor was credited as the inventor of radio and became rich. Wardenclyffe Tower became a 186-foot-tall relic, and the defeat, Tesla's worst, led to another of his breakdowns. It is not a dream, Tesla said, it is a simple feat of scientific electrical engineering, only expensive-blind, faint-hearted, doubting world! ${ }^{10}$

\subsection{Research, freedom and responsibility}

It is obvious today that our day-to-day lives is closely tied to the increasing development of science and the technical innovations that it has spawned. Information and new technology, biology, physics, engineering and chemistry have all markedly changed our lives during the past century. Or this progress depend in large part on scientific research, this fact puts scientists in a particular position. Indeed, he is the super experts', who are expected by the public to provide expertise and knowledge to solve societal problems. But, in the same time many people remain cautious and even fearful of the technological and medical progress enabled by scientific research. So the society assign scientists a high degree of responsibility and we expect them to dedicate themselves to the benefit of humanity.

${ }^{\mathrm{f}}$ He blocked Tesla project about a Radar design, using his quality of Senior Advisor. 
Are scientists responsible for the potentially negative impacts of their work?

From Sophistry point of view, the answer is clearly no! The researchers are not responsible for how society use science. But what in case where the impacts they intend and those which do not intend were foreseeable in some way, here the question of the responsibility became difficult to ignore. Of course, we are not saying that the impacts, whatever their nature beneficial or harmful, are of solely scientists's moral responsibility, because other people can be involved and should bear responsibility for the part of decisions and actions. For instance, if a terrorist used some knowledge generated by researchers, they are foremost responsible for their heinous act. But in case where the harmful impact of the produced knowledge is foreseeable, the scientists will have his part of the responsibility in some level of the decision to develop such knowledge. Let us consider the case of building a virus like smallpox from the ground up or how to create other pathogenic, tailored organisms targeted either to humans or the foods on which we depend. In this case, the use for nefarious purposes of this knowledge is foreseeable, the researcher who introduce and develop such technological capacities share his part of responsibility for an attack that could ultimately cause death. We can no longer hope naively that people will only use science for the public good. Today, we should recognize the diversity of the sociopathic members of our society, some of whom will also be intelligent enough to use the results of science.

So again, do scientists really have a greater responsibility to contribute to society than, say, politicians, judges or any other of us? And if so, can we define this responsibility?

Here, we have to be careful and distinguish between the special cases and the more general case. At the historical side, we have many examples of how certain scientists acted in extreme situations, and whether they showed an awareness of or commitment to a special responsibility.

Wernher von Braun ${ }^{\mathrm{g}}$ (1912-1977) is an example of a scientist so enthralled by his work that he did not spare much thought for the societal and political consequences of how it was used. He was called an "amoral opportunist". ${ }^{23}$

Confronted with the damage caused by the V-2, he might have said "this is not my department". Another example, Fritz Haber who reflected the patriotic attitude of the society in which he lived. ${ }^{\mathrm{h}}$

\footnotetext{
$\mathrm{g}$ Von Braun was a brilliant engineer and rocket scientist who was fascinated with space flight from a young age. He joined the Spaceflight Society in Berlin in 1930, for which he built and tested liquid-fuel rocket motors. The US government were well aware of his valuable expertise and quickly approved the transfer of Von Braun and many of his engineers to the USA, where Von Braun started a new career building rockets. Von Braun became Director of the Marshall Space Flight Center in Huntsville, Alabama, in 1960.

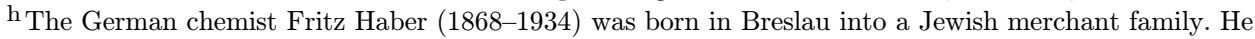
and Carl Bosch developed the so-called Haber-Bosch' process to synthesize ammonia from hydrogen and atmospheric nitrogen. In 1919, Haber was awarded the 1918 Nobel Prize in Chemistry for this work. Regarding his role in the First World War, he said: "During peace time a scientist belongs to the World, but during war time he belongs to his country". Nevertheless, after the suicide of his first wife in 1915, Haber expressed, perhaps transiently, doubts about his actions.
} 
Edward Teller (1908-2003) and Andrei Sakharov (1921-1989) were both crucially involved in developing thermonuclear bombs — the most destructive weapons ever invented by mankind. In contrast with Teller, however, Sakharov became a popular critic of his country's political and military goals after recognizing that the so-called balance of nuclear terror' might lead to disaster.

Of course, we are aware that these are rather extreme examples of the interpretation of scientists of their special responsibility, but still we can nevertheless derive some lessons. First, it is almost impossible to keep an invention secret, even if it has great military value or can do enormous harm. Second, a respected scientist, or group of scientists, can exert enormous influence on politics and society. So, as we can note all four of these men worked on weapons of mass destruction and death, and as with general society, they vary in their behavior. Each had different justifications and reactions to the use of their science: some claimed to be patriots, others were wilfully ignorant of the wider use of their work and one of them realized the harm he had done and dedicated his life to remedying it.

Though things have changed today and a fortiori our world has certainly changed since the First World War, and most scientists in Western societies are now supported by public money and enjoy much more freedom than their predecessors, the question of responsibility has, however, not gone away. Numerous technological advances, from the internet to image recognition and autonomous drones enrich always the debate about the application of research.

In different domains of research, we have even more sensitive cases. Indeed, irrespective of the dangers of misuse or the putative development of new therapies, the experiments with mousepox, polio and influenza raised awareness of biosafety issues and triggered a flood of comments from scientists, politicians and members of the public, which we might consider a good thing.

Research cannot be regulated before its dual-use nature becomes apparent, we need to raise awareness among scientists about the possibility of adverse uses of their inventions. The universities and research institutes should have a much more proactive role in raising awareness and supporting responsible behavior through explicit declarations. Some can suggest the usual counter-argument that this would restrict the freedom of research and education', but this is not valid, the education to enhance a sense of responsibility for the consequences of their work among scientists is not an obstacle to freedom of research.

Fritz Haber, Edvard Teller or Wernher von Braun were products of the societies in which they lived, in which they were educated, and in which they worked and sought recognition for their work. This problem remains today. As much as we might appreciate the expertise and knowledge of individual scientists, they will almost always behave in accordance with the values of the societies in which they work. This puts the onus on all of us, not only on the scientists. All of us should feel responsible for upholding moral values, for educating the next generation about those values and for making responsible decisions about the use of inventions. 
Consequently, we scientists are somehow responsible for both what they intend to achieve and that which is readily foreseeable, as we all are. So the fact of becoming a scientist does not remove this burden of responsibility. The burden can be shared, ${ }^{\mathrm{i}}$ or alternatively, they could decide (and it has been proposed) that some forms of regulation ${ }^{\mathrm{j}}$ should be imposed to reduce the risks. So we find ourselves face a tension: the more oversight scientists submit to, the less responsibility they bear, but it comes at the cost of the freedom to choose the type of work they can do and how they do it. As long as there is freedom of research, there is the responsibility that comes with it.

\subsection{Obsolescence as argument of progress}

On 23 December 1924, a group of representatives from all the major lightbulb manufacturers, including Germany's Osram, the Netherlands Philips, Frances Compagnie des Lampes, and the United States General Electric, gathered in Geneva. The group founded the Phoebus cartel, a supervisory body that would carve up the worldwide incandescent lightbulb market. It was the first cartel in history to enjoy a truly global reach. ${ }^{\mathrm{k}}$ Its far more enduring legacy was to engineer a shorter life span for the incandescent lightbulb. By early 1925, this became codified at $1000 \mathrm{~h}$ for a pear-shaped household bulb, a marked reduction from the 1500 to $2000 \mathrm{~h}$ that had previously been common.

All evidence points to the cartels being motivated by profits and increased sales, not by what was best for the consumer. In carefully crafting a lightbulb with a relatively short life span, the cartel thus hatched the industrial strategy now known as planned obsolescence.

In 1932, in the midst of the Great Depression, Bernard London wrote in his essay "Ending the Depression Through Planned Obsolescence". ${ }^{27}$

"People everywhere, in a frightened and hysterical mood, are today disobeying the law of obsolescence. They are using their old cars, their old tires, their old radios and their old clothing much longer than statisticians had expected on the basis of earlier experience. Society, therefore, is suffering untold loss in foregoing the workpower of ten million human beings". According to London, "in the present inadequate economic

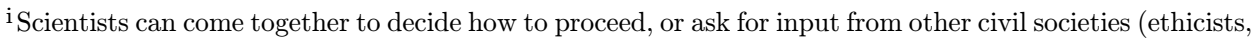
social scientists) and the broader public.

$\mathrm{j}$ Either in the selection of projects or in the control and dissemination of results.

$\mathrm{k}$ The rapid spread of electrification and the introduction of new forms of lighting like bicycle lamps, car headlights, and streetlights in the early 20th century, did offer nearly limitless opportunities for inventors and entrepreneurs. But as thousands of manufacturers vied for market share and a technological edge, no single company felt assured of stable sales from one year to the next. That was as true for tiny backroom operations as it was for the giant corporate entities with multinational factories and research laboratories. Immediately, preceding the cartels formation, for instance, Osram experienced a dizzying drop in its German sales, from 63 million lightbulbs in the financial year 1922-1923 to 28 million the following year. Not surprisingly, Osram head William Meinhardt was the first to propose the arrangement that eventually became the Phoebus cartel.
} 
organization of society, far too much is staked on the unpredictable whims and caprices of the consumer. Changing habits of consumption have destroyed property values and opportunities for employment. The welfare of society has been left to pure chance and accident. Briefly stated, the essence of my plan for accomplishing these much-to-be-desired-ends is to chart the obsolescence of capital and consumption goods at the time of their production."

What had to be said was said, for him, growth was too serious a matter to be left to consumer confidence. About consumers implications Brooks Stevens (1911-1995) wrote: "Planned obsolescence instills in consumers the desire to own something a little newer, a little better, a little sooner than is necessary". ${ }^{28}$

Philip Kotler, a famous professor of marketing strategy at Northwestern University and supporter of Stevens remark: "Much so-called planned obsolescence is the working of the competitive and technological forces in a free society forces that lead to ever-improving goods and services". ${ }^{30}$ According to him, planned obsolescence would somehow be the heart and the engine of a market economy.

Note that planned obsolescence ${ }^{l}$ is not necessary a univocal evil. There is what we call "pseudo-functional obsolescence" part in which we introduce a mere cosmetic changes that improve neither utility nor performance and constrain towards replacement for all the wrong reasons. It is difficult to detect because it readily comes under the guise of innovative design, a strategy that not only creates frustration among consumers, but that has proven to be quite harmful to our environment sometimes.

So, the fact that companies are investing considerable energy and sums to deliberately produce defective products, and the idea that resources are finite is once more emerging, make planning obsolescence appears as a dreadful conspiracy ${ }^{\mathrm{m}}$ of the consumer, and at worst, as a material crime against the environment.

So, 80 years after Bernard London, optimism has given way to doubt, at least in developed countries. Designing products so that they quickly cease to be useable is considered as commercial treachery and deception. It shall come as no surprise then that "green" movements all to easily denounce this contradiction, at the very time that the money required to fund the ecological transition is scarce. The ideal world of circularity.

\footnotetext{
${ }^{\mathrm{l}}$ It should be noted that the concept of planned obsolescence only concerns mass-market consumer goods. The luxury industry, and that is especially true regarding extreme luxury, works with the opposite principle, that of eternal security. Faced with this durability of products, the one who is going to himself experience obsolescence is the consumer himself.

m Apple's increasing use of tamper-resistant screws can be seen as a form of planned obsolescence. Indeed, Apple is using proprietary five-point security screws in the iPhone 4 and new MacBooks Airs. The special screws were first used in the 2009 MacBook Pro to stop users from replacing the battery. The screws are unique to Apple and serve one purpose only: to keep users out. Or this force customers to upgrade their gadgets sooner than necessary. They also make them reliant on Apple for expensive repairs and upgrades. General Motors invented planned obsolescence in the 1920s. Apple is doing the same thing.
} 
Conversely, there is also a good side to plan obsolescence, what we call the "value engineering" argument, where the analysis of value is done already at the design phase level. The aim is to use as little material as possible and reduce waste, while providing an acceptable lifespan. A simple example: the material used for mobile devices, given the pace of technological advances in telecommunications, it would be pointless to build a mobile phone capable of lasting 10 years. So, this point of view positive planned obsolescence protects the environment. In theory, however, planned obsolescence is not doomed to lead to wastefulness. If nothing were ever discarded, if the economy were perfectly circular, all behaviors would be acceptable. But it would take tremendous progress in recycling for this to happen, and it would also require that the products, which are presently designed to be quickly outdated, are henceforth made in order to readily optimize the recovery and recycling of the rarest raw materials they contain.

\section{The Manhattan Project}

Throughout history, science has been plagued with religious and political pressure and even persecution. The intrusion of such "irrelevant" social institutions, the scientists believed, threatened the right to free inquiry and was wholly inconsistent with the methods of science. If those institutions did not set an agenda for science or abuse the scientists' discoveries through application, they introduced an unwanted bias into an objective exploration. Consequently, scientists have agreed to maintain a wall separating the laboratory from worldly affairs in order to protect the purity of their profession against outside forces. ${ }^{\mathrm{n}}$ As a side effect, this wall that has kept worldly pressures out of the scientific realm has also served to keep scientists out of the worldly realm. Though it was intended to protect science, it has effectively silenced the political opinions of its practitioners.

In fact, an attitude has been fostered that "the best way to ruin the effectiveness or integrity of [the scientific profession] is to have it get involved in public questions where it has no special expertise ${ }^{7}$

\footnotetext{
${ }^{\mathrm{n}}$ Here some remarks are in order. We can question the statut of this wall and advance the idea that the wall itself is in somehow the "reason of pressure on science". Indeed, in fact the implication of such construction is that the dynamical influence is not unique and is not the same on all the fields of sciences and specialities. It depends on the sector of activities and how much it is tied with other social activities. For instance, in Mathematics, the role played by this separation is not trivial and it is different from applied physics, where the financial dependence of the laboratories is evident. It is clear that it is easier for mathematicians (at the first degree) to keep distance with the worldly affairs than the applied physicist, but in some degree only. Because once we find an application of some structures and ideas from mathematics, the domain itself became again zone of control. As we can see with the cryptography and information coding and some of financial activities for example. And even in two near sectors as in applied and theoretical physics, the sources of the "Big Sciences" and "small science", the "small science" undergoes the effect of this wall more than the big science. ${ }^{29}$ The rise of extremely large projects is but one of several pressures on researchers conducting small-scale projects.
} 
Scientists, who are free to develop political consciousness and opinions, are perceived as impure if they connect their profession with national affairs. This sense of scientific purity can, however, lead to elitist beliefs ${ }^{13}$ :

The peculiarity of science is that the principles which are used to excuse social irresponsibility have been elevated into a more or less coherent ideology. This ideology. [,] by setting science itself above all other human values [,] has a powerful influence within the psyche of every scientist and in society as a whole.

This wall, based on ethos and historical experience, acts to ensure scientific purity; it purges both professional knowledge and the physicists themselves of subjective elements by restricting interaction between the scientific and the worldly.

The prevalent attitude of scientists as a group has been that they should not as scientists become politically engaged. The purists tend to think that good scientists are not political activists and that those who do become active are temporarily indulging an idiosyncratic personal need..$^{13}$

This attitude is evident in the life of J. Robert Oppenheimer, wartime director in Los Alamos, New Mexico. In the first half of the 20th century, Oppenheimer "never read a newspaper or a current magazine..."

"I had no radio, no television; I learned of the stock market crack in the fall of 1929 only long after the event; the first time I ever voted was in the presidential election of 1936." 26 Shortly after World War II, he wrote:

I was deeply interested in my science, but I had no understanding of the relations of man to his society. ${ }^{14}$

This wall that isolated Oppenheimer would be challenged by the events surrounding and flowing throughout the Manhattan Project. ${ }^{14}$ Here, science became so unambiguously political that the physicists themselves became liaisons between the two realms. Here, many physicists perceived such unprecedented duties and legitimacy to act that they overcame the inertia of scientific purity. Because nuclear weapons were first created in the midst of World War II, it was impossible for most contemporaries to consider the issues at stake. Manhattan Project security demanded that the bomb be kept secret from the American public, and consequently very few people could deter or influence the invention.

Those political and military leaders who could have spoken out were never inclined to do so because it was their job to win the war. Therefore, the only people who remained to question the social, moral, and political implications of the atomic bomb were the scientists who invented it. The World War II manifestation of Fosdick's dilemma calls ${ }^{3}$ for an examination of the political activity of Manhattan Project physicists before Hiroshima. 
The problem was, however, more complicated. When physicists met with politics, their conception of scientific purity was challenged. Pure science had traditionally been defined in terms of detachment from the rest of societal affairs. In order to protect their autonomous right to free investigation, scientists found it prudent to "insist that scientific knowledge is strictly objective and neutral, and that the professional work of scientists... is of no particular political significance."

Therefore, simply practicing explicitly political or military work was inconceivable to physicists in the late 1930s. Certain forces could, however, lead scientists into political realms: when Germany invaded Poland, asserts Rotblat, ${ }^{6,4}$ it seemed

"the whole of our civilization was in mortal peril. My scruples were finally overcome."

When scientists finally enlisted in political-military projects, they were faced with the choice of whether or not to help define the project itself. That is, should scientists serve as tools of the state, or should they also help to direct its political objectives?

Once again, the traditional role of the physicist prescribed a compartmentalized, detached position: many argued that "By mixing the two [politics and profession] you will dilute your effectiveness as an objective scientific observer. It is also claimed that this mixing-in of politics will dilute or destroy the "holiness" of science". ${ }^{6}$

With the Manhattan Project, however, many physicists would redefine purity and thereby their relation to society. J. H. Rush reflected in 1947, "Science had become politically interesting, and scientists had become interested in politics ${ }^{21}$ ". On the one hand, the physicists were dedicated to their project and to helping the United States win the war. On the other hand, they had grave doubts about the effects their work would have on the postwar world. This conflict forced the scientists to take opposing positions as professionals and citizens.

When its eager inventors confront the bomb's incredible destructiveness, they recoil. Albert Einstein gropes for the right English words to urge the President to make a Uranium bomb, then, years afterward, disowns the creation in disgust. Danish physicist Niels Bohr travels across the Atlantic to enlist the aid of scientists, only later to repeat the journey with dark prophecies of an arms race.

J. Robert Oppenheimer drives himself to exhaustion to solve the puzzle of how to sustain an explosive nuclear reaction. Yet as he watches the first atomic fireball rise from the New Mexican desert, he thinks only of death and destruction. ${ }^{15}$ This internal conflict led the physicists to build bombs while talking peace. Having committed themselves to building a nuclear weapon, the scientists advocated using it to establish an international organization to control the atom and prevent future wars. Science collided with politics because of World War II.

Physicists then assumed political roles because their perceived duties and legitimacies overcame the inertia of scientific detachment. Purity was redefined as involvement in, not separation from, the worldly implications of scientific 
discoveries. With World War II, however, physics was acknowledged to have worldly implications.

"Scientists saw the successful application of basic principles result in violent success during the war. The effects of science on our society could no longer be ignored". ${ }^{16}$

Science could consequently be made to serve political ends.

"Never again would or could a government relegate the scientist to a secondary position. [because] science research had become a major element in national power". ${ }^{16}$

Scientific contributions to international warfare redefined both worlds and bound them together for the future. The relationship between science and state, "became tied to the political and national defense issues generated by the cold war. As a result, the boundary between science and politics blurred....". ${ }^{21}$

Finally, the physicists became experts.

\section{Values in Science}

So scientists bring more than just a toolbox of techniques to their work. Scientists must also make complex decisions about the interpretation of data, about which problems to pursue, and about when to conclude an experiment. They have to decide the best ways to work with others and exchange informations. Taken together, these matters of judgment contribute greatly to the craft of science, and the character of a person's individual decisions helps determine that person's scientific style (as well as, on occasion, the impact of that person's work). Much of the knowledge and skill needed to make good decisions in science is learned through personal experience and interactions with other scientists. But some of this ability is hard to teach or even describe. Many of the intangible influences on scientific discovery - curiosity, intuition, creativity - largely defy rational analysis, yet they are among the tools that scientists bring to their work.

When judgment is recognized as a scientific tool, it is easier to see how science can be influenced by values. Consider, for example, the way people judge between competing hypotheses. In a given area of science, several different explanations may account for the available facts equally well, with each suggesting an alternate route for further research. How do researchers pick among them?

The rise of extremely large projects (and growing military research) is but one of several pressures on researchers conducting small-scale projects. Most fundamental is the sheer growth in the number of practicing scientists and engineers. Unfortunately, this has an impact on the number of grants and the chances of getting a grant, in our case they have fallen. Another concern is the cost of research. As we expected it is going up rapidly as demands rise. This is tied with question of laboratory safety and environmental protection and the universities charge and the costs of the new high 
performance equipments needed for research. The result is that the scientific inflation rate exceeds sometimes that of the civilian economy. This could be the cause of decline or holding steady of many areas, an example is condensed-matter physics, one of the hottest areas of science. It studies of such esoteric phenomena as photon and electron transport which have yielded advances in computer chips, tiny semiconductor lasers, the liquid crystals of computer displays, optic devices, composite materials of extraordinary strength and so on, not to mention human sciences sector.

We note today in many countries, that the foundation's budgets for most small ventures in mathematics, physics, chemistry and computer science have recently fallen below their 1988 levels. Of course, behind the numbers is hiding the issues of lost opportunities.

\subsection{Knowledge-based economy}

Knowledge is now recognized as the driver of productivity and economic growth, leading to a new focus on the role of information, technology and learning in economic performance. The term "knowledge-based economy" stems from this fuller recognition of the place of knowledge and technology in modern economies. Most of the analysis is increasingly directed to understanding the dynamics of the knowledge-based economy and its relationship to traditional economics, as reflected in "new growth theory". The growing codification of knowledge and its transmission through communications and computer networks has led to the emerging "information society".

Scientific research and the ensuing knowledge are therefore understood as values in themselves that do not necessarily need to be usable. They benefit everyone and often become the basis for new and valuable applications. In addition, knowledge is a public good, not something that one can refuse to share with others. The results of publicly funded academic research belong to society after publication and are not the personal property of the individual scientist. Consequently, scientists have an obligation to reach out to the populace and explain what they are doing, why they are doing it and what implications it will have on daily life.

The need for workers to acquire a range of skills and to continuously adapt these skills underlies the "learning economy". The importance of knowledge and technology diffusion requires better understanding of knowledge networks and national innovation systems. Most importantly, new issues and questions are being raised regarding the implications of the knowledge-based economy for employment and the role of governments in the development and maintenance of the knowledge base. Identifying "best practices" for the knowledge-based economy is a focal point of the majority of work in the field of science, technology and industry.

\section{Managing the University}

Even if the majority of the European universities became autonomous institutions, their governance structure is still organized under the laws of each state, which expressly states the functions and management structures together with their 
attributions. For example, for the past five years, the french academic environment (and other countries also) experienced a consistent reform. In the educative system, a new Law of National Education were voted and which represented, the starting of the modernization of the academic education, the modernization of higher education institutions management, reinforcing university autonomy and the public liability, insuring quality in academic education, competition financing, developing transborders cooperation, both at the Community level and globally. In the university management, we see today a review of governance structures focus on the new models, which re-distribute the decision making power and responsibilities between internal and external, deciders from local community, stakeholders, leaving behind the traditional self-governance model. ${ }^{\circ}$

Actually, we witness managerial-type orientations at the level of higher education institutions. ${ }^{\text {p20,22 }}$ Indeed, this type of orientation are increasingly promoted and encouraged to start entrepreneurial initiatives, especially through the stimulation of the public-private partnership. An accent is being placed on developing management abilities by increasing competition between universities for obtaining the financing they need for fulfilling their assumed missions. More than that, we must not neglect the increased responsibility of leaders and leading structures from universities, through the extended freedom they received in administrating study programs, or their internal organization, structure and functioning.

However, after a critical analysis of the situation, we now think that, despite significant progress registered by big number of academic education institutions, one needs to admit that not all universities currently benefit from an authentic leadership, as the system continues to face serious faults in management. This is mainly due to the absolute majority and manager system currently applied in the major part of the universities, eroding thus any discussion concerning the governance and the decision-making system.

\subsection{Knowledge, expertise and politics}

Despite an increased level of education and a growing interest in scientific and technological topics, society still needs expert advice in nearly all areas of life. Consequently, many experts have gained considerable influence over public opinion and policy making. ${ }^{\mathrm{q}}$ Note that scientists and general public do not share the same

\footnotetext{
o The concept of governance in postsecondary education refers to the internal structure, organization and management of autonomous institutions. The internal governance organization typically consists of a governing board (board of regents, board of directors), the university president (executive head, CEO) with a team of administrative chancellors and staff, faculty senates, academic deans, department chairs, and usually some form of organization for student representation. Management structures themselves have become increasingly complex due to the increasing complexity of intraorganizational, interorganizational and governmental relationships. ${ }^{18,19}$

pWith different degrees from country to another.

q Some have even acquired a mythical status as Nikola Tesla. It is this mythical aspect of his personality mixed with his technological and innovation insights which made Tesla a subject of constant observation by the FBI (see https://vault.fbi.gov/nikola-tesla).
} 
view concerning the credibility and the relevance of a theory or a statement. ${ }^{\mathrm{r}}$ Indeed, for scientists, relevance and credibility are the result of a logical chain of arguments that are supported by experimental proof. By contrast, plausibility and general agreement play central roles in public debates. It is possible that a plausible public statement contains no truth whatsoever, whereas a scientific theory backed by a wealth of research data is not credible to a non-scientific audience. ${ }^{17}$

People trust in the honesty and credibility of scientists has always been high in all technological or scientific civilizations. Remark that this faith rests on the reliability and resilience of the knowledge that scientists produce and the fact that they constantly submit it to internal quality control. As every researcher depends on the validity of others' information, the basic rules of good scientific practice are widely followed. This trust and honesty are thus the basic characteristics of the process of knowledge production, and there is no other profession in which these are as fundamental as in science. In politics, disinformation, secrecy, half-truths and refusal to help are part of the game. Creating knowledge obviously follows different rules than creating value or power. ${ }^{1}$

However, when scientists try to explain their work and their results to a general audience, they have a problem in terms of content as well as language. Indeed, to create maximum objectivity, scientific language has evolved a unique style and rules. As a consequence, scientific texts are depersonalized, ${ }^{\mathrm{S}}$ which is amplified by the fact that authors are not allowed to "tell a story", although there is often a personal tale behind the discovery. Another limitation is the ban on metaphors and images to understand complex facts, which makes scientific texts particularly hard to read. In addition, a scientific paper is very formally structured into materials and methods, results and discussion sections. From the point of view of communicating science to the public, the traditional model of the scientific text is the least effective method.

But when exposed to the media, the renowned expert is suddenly fully exposed to the agora of the public opinions. Consequently, a good scientist who is used to the rules of scientific discourse is thus in an unfortunate position. ${ }^{t}$ After such an experience, the scientist vows never to take part in such a debate again, thus reducing the number of experts who are willing to publicly discuss science. But such debates can take place without a scientific expert if politicians and lobbyists use arguments from

\footnotetext{
${ }^{\mathrm{r}}$ However, the public is often not aware of another intellectual quality that is probably even more important to scientific endeavor and the creation of robust and reliable knowledge: the scientific debate. It plays such a central role in science that Werner Heisenberg once commented: Science emerges from debate. $^{32}$

s The preferred style is passive.

${ }^{\mathrm{t}}$ This is particularly true if a scientist is asked to take a position in a conflict that involves conservative values, such as biotechnology (this remind us the Monsanto affair, and the pharmaceutic industry monopole), research with human embryonic stem cells, organ transplantation, evolutionary theology or animal experimentation. The scenario is always the same. Research has successfully come up with a possible solution to a social problem. This new knowledge triggers futuristic expectations in the media, and critics and lobbyists enter the debate. Hopes and fears are created: the agora has its new conflict. The public views the scientist as a representative of technological progress, thus eliminating his role as an objective and honest expert.
} 
scientific studies that represent differing views but cannot be compared in terms of material and methodology. ${ }^{\mathrm{u}}$

A particularly difficult situation arises if two experts are asked to comment on a new problem. ${ }^{\mathrm{v}}$ In times of crisis, the lay public expect assurances which science often cannot provide. Experts are therefore forced to give short categorical judgements while critics insinuate that the expert is influenced by economic interests, ${ }^{\text {w }}$ has no real grasp of the problem and is subject to "community pressure" in other words, they are more concerned about their peers than about public opinion. Whether media training is sufficient to avoid these traps is not clear. But it is obvious that as soon as a scientist leaves the laboratory and enters the agora, he (she) must be ready to play under completely different rules.

\section{Conclusion: What is an Idea Worth?}

The answer, of course, depends on the idea. How much is it worth to society for someone to figure out how to inter-link documents on line ${ }^{\mathrm{x}}$ ? To devise a scanner that can image cancers under the skin? Or why the sky is blue?

It is often forgotten that such ideas do not happen in a vacuum. They are born of collaboration between basic research and applied science, between idea and innovation. Yet people often speak of basic and applied as if we have a choice. We do not. Basic and applied science form a virtuous circle, and we break it at our peril. Take the example of electric lighting. A mere 150 years ago the candle was the main source of artificial light. By then, it had already been developed to a very sophisticated degree. But no amount of research on the candle would have given us the electric light bulb. For that, you need basic science to prepare the way. But basic science alone would not have given us the light bulb. Scientific progress needs Edison's as well as Faraday's. And when applied research finds utility in a discovery such as electricity, it not only improves society, but gives new tools back to the basic research endeavor: the virtuous circle.

\section{Acknowledgments}

We would like to thank the reviewers for their thorough review and highly appreciate their comments and suggestions, which significantly contributed to improving the quality of the publication and have enriched the content of this paper.

\footnotetext{
${ }^{\mathrm{u}}$ For instance, the question concerning the Sustainable Development, pollution and Renewable Energy sector.

${ }^{\mathrm{v}}$ For instance, the case of the Environment and global warming.

${ }^{\mathrm{w}}$ As in the pharmaceutic industries and the doctor community case and the recent management of economic crises by the banks.

x By inter-link documents on line, we mean: introduce the web links between the html and php web pages as the simple case, but there is more complicated correlated links also, etc., i.e., what is the price to imagine such idea!
} 


\section{References}

1. P. Weingart, Die Stunde der Wahrheit? Weilerswist (Velbrück Wissenschaft, Germany, 2001).

2. K. R. Popper, The Logic of Scientific Discovery (Basic Books, New York, 1959).

3. R. B. Fosdick, The Old Savage in the New Civilization (Doubleday, Duran and Company, New York, 1929), pp. 23-24.

4. J. Ziman, Basic Principles, in Scientists, the Arms Race and Disarmament: A UNESCO/ Pugwash Symposium, (Taylor and Francis Press, London, 1982), p. 172.

5. About Planned Obsolescence, the "light bulb" case see: https://vimeo.com/55490083 About "Inside Job" see: https://www.youtube.com/watch?v=IVrRMpNP5q4 (2010).

6. J. Rotblat, Leaving the bomb project, Bull. At. Sci. 41 (1985).

7. M. Brown, The Social Responsibility of the Scientist, Vol. 33 (Free Press, New York, 1971).

8. H. A. Waxman, Politics and Science in the Bush Administration (United States House of Representatives, Special investigations division, 2003).

9. G. Sims, The Galileo Affair (Scepter Press, 2007).

10. N. Tesla, My Inventions: The Autobiography of Nikola Tesla (Hart Brothers Publication, 1982).

11. M. Cheney, Tesla: Man Out of Time (Touchstone, 1981).

12. G. King, The Rise and Fall of Nikola Tesla and his Tower.

13. J. Fanton et al., The Manhattan Project: A Documentary Introduction to the Atomic Age, (Temple University Press, Philadelphia, 1991).

14. J. R. Oppenheimer, Encouragement of science, Bull. At. Sci. 7(1) (1951) 6-8.

15. J. R. Oppenheimer, Speech to the Association of Los Alamos Scientists, Los Alamos, in Robert Oppenheimer Letters and Recollections, eds. A. K. Smith and C. Weiner (Harvard University Press, 1980), pp. 315-325.

16. J. Simpson, The scientists as public educators: A two year summary, Bull. At. Sci. (1947) 243.

17. G. W. Kreutzberg, Glaubwrdigkeit auf dem Marktplatz der Meinungen, in Wissenschaft Erfolgreich Kommunizieren, K. von Arentin and G. Wess (ed.) (Wiley-VCH, Weinheim, Germany, 2005).

18. A. Kezar and P. D. Eckel, Meeting today's governance challenges, J. High. Educ. 75(4) (2004) 371-398.

19. A. Kezar, Understanding and Facilitating Organizational Change in the 21st Century: Recent Research and Conceptualizations (ASHE-ERIC Higher Education Reports, Washington, DC 2001).

20. A. Kezar and P. D. Eckel, The effect of institutional culture on change strategies in higher education: Universal principles or culturally responsive concepts? J. High. Educ. $\mathbf{7 3}(4)$ (2002) 435-460.

21. A. K. Smith, A Peril and a Hope: The Scientists' Movement in America, 1945-47 (The MIT Press, Cambridge, 1970).

22. B. M. Gourley, In The Globalization of Higher Education, Chap. 18 (Economica Limited, 2008), pp. 207-216.

23. M. Neufeld, Von Braun, Dreamer of Space, Engineer of War (Alfred A. Knopf, New York, 2007).

24. S. Lapworth, Arresting decline in shared governance: Towards a flexible model for academic participation, High. Educ. Q. 58(4) (2004) 299-314.

25. M. Hiltzik and B. Saouer, Big Science: Ernest Lawrence and the Invention that Launched the Military-Industrial Complex. 
26. D. J. de Solla Price, Little Science, Big Science and Beyond (Columbia University Press, 1986).

27. B. London, Ending the Depression Through Planned Obsolescence (1932).

28. J. Holusha, Brooks Stevens, 83, Giant in Industrial Design (The New York Times, 1995).

29. W. J. Broad, Big Science; Is it Worth the Price? Small-Scale Science Feels the Pinch from Big Projects (The New York Times, (Science), 1990).

30. P. Kotler, Marketing Management: Analysis, Planning, and Control, 1st edn. (PrenticeHall, 1972).

31. Eurydice, Higher Education Governance in Europe, doi: 10.2766/29900 (2008).

32. W. Heisenberg, Der Teil und das Ganze (R. Piper, Munich, Germany, 1969). 